\title{
Natureza administrativa das instituições de Ensino Superior, gestão organizacional e o aces- so aos postos de trabalho de maior prestígio no mercado de trabalho
}

Antônio Augusto Pereira Prates Matheus Faleiros Silva ${ }^{2}$ Túlio Silva de Paula ${ }^{3}$

Resumo: Este artigo discute a relação entre o efeito do tipo de gestão organizacional de instituições de Ensino Superior e seus efeitos sobre o desempenho dos seus formandos no mercado de trabalho em termos de acesso a postos de maior pretígio ocupacional (PRATES, 2007; 2010). O artigo reúne dois estudos independentes sobre essa questão. 0 primeiro é um estudo de caso, realizado em 2008, com professores de instituições privadas de Ensino Superior e de uma universidade pública, a EACH (USP-Leste). O segundo, um estudo quantitativo realizado, em 2011, com dados da PNAD 2007, no intutito de testar, via modelos de regressão linear, se o tipo de instituição - pública ou privada, e o tipo de curso, bacharelado ou tecnológico - afeta o desempenho dos estudantes por elas formados em termos de acesso diferenciado à postos de trabalho com maior prestígio. A conclusão principal, porém não definitiva, é que a hipótese de Prates $(2007 ; 2010)$ é bastante plausível, ou seja, que o ambiente institucional interno, gerado pelo tipo de gestão organizacional da instituição de Ensino Superior, afeta o nível de desempenho dos estudantes para o acesso à postos de maior prestígio ocupacional no mercado de trabalho. Palavras-chave: Clima Acadêmico, Instituições Profissionalizantes, Prestígio Ocupacional, Capital Cultural, Mercado de Trabalho

\section{Introdução}

A questão básica deste artigo pode ser enunciada da seguinte forma: a diferenciação institucional entre universidades de pesquisa e instituições vocacionais de Ensino Superior tem comprometido o efeito potencial de democratização que poderia ter sido produzido pela enorme expansão do
Recebido:

02.08.2011

Aprovado:

25.04.2012

1. Professor Associado do Departamento de Sociologia e Antropologia da Faculdade de Filosofia e Ciências Humanas (FAFICH) da Universidade Federal de Minas Gerais (UFMG).

E-mail: aaprates@ oi.com.br

2. Mestre em Sociologia pelo Programa de Pós-Graduação em Sociologia da Universidade Federal de Minas Gerais (UFMG).

E-mail:

matheus faleiros@ yahoo.com.br

3. Mestre em Sociologia pelo Programa de Pós-Graduação em Sociologia da Universidade Federal de Minas Gerais (UFMG).

E-mail:

tuliosilva85@gmail. com 
sistema de Ensino Superior a nível mundial? Essa questão envolve um dilema persistente e conhecido na literatura especializada (SHAVIT et al., 2007; RAFTERY \& HOUT, 1993; LUCAS, 2001 apud COLLARES, 2010; PRATES, 2005, 2007), qual seja, a expansão do sistema do Ensino Superior nas sociedades contemporâneas não quebrou os entraves estruturais que impedem os candidatos de baixa renda de chegarem às universidades de elite que formam os quadros potenciais dos postos de maior prestígio no mercado de trabalho, tanto no setor público quanto no privado. Além dos fatores conhecidos relacionados ao background familiar dos candidatos ao Ensino Superior, tais como, status socioeconômico e educação dos pais, raça e gênero, uma das razões principais desse dilema é o tipo de gestão organizacional que preside um e outro tipo de instituição de Ensino Superior.

Nossa proposição central é que instituições de Ensino Superior voltadas para a produção acadêmica são as únicas capazes de produzir capital cultural quase equivalente ao produzido pelo background familiar. Como os postos de trabalho que gozam de alto prestígio requerem, além de capital humano, certo nível de capital cultural, que se traduz em sofisticação cognitiva funcional para se adequar ao perfil desses postos, o grande contingente de pessoas que acessa o nível superior via instituições "vocacionais" fica "fora" da competição pelos altos postos do mercado de trabalho. No Brasil, a expansão do sistema de Ensino Superior tem ocorrido com base em instituições privadas e essas instituições, não por serem de natureza privada, mas por adotarem um modelo de gestão próprio das organizações empresariais, não criam, como no caso das instituições vocacionais, o capital cultural minimamente necessário para seus formandos escalarem as barreiras colocadas no alcance de postos de trabalho de prestígio no mercado. Essa discussão pode, também, referenciar-se na proposição de F. Hirsch (1977, apud SCHWARTZMAN, 2011) que identifica uma tensão entre duas dimensões da educação: a posicional ou de prestígio, associada aos títulos obtidos; e a dimensão absoluta ou de formação de capital humano.

Este artigo pretende discutir o dilema através de dois estudos distintos. O primeiro é um estudo de caso de instituições privadas que tenta identificar variações de gestão e clima organizacional e a percepção dos professores sobre a sua capacidade em criar capital cultural. O segundo é um estudo quantitativo que busca analisar os efeitos da natureza administrativa das instituições de Ensino Superior sobre o "desempenho" dos seus formandos no índice de prestígio ocupacional das ocupações no Brasil. Embora os dois estudos não tenham sido concebidos simultânea e organicamente, eles são parte de um Programa de Pesquisa mais amplo sobre o sistema de Ensino Superior. 


\section{A questão da diferenciação institucional}

Como sugerido por Prates (2007, p. 105-6), “o termo diferenciação institucional tem sido utilizado na literatura especializada para denominar um processo de diversificação funcional entre as instituições de ensino de nível terciário". Tal processo de diferenciação estabelece papéis distintos para as "históricas" e clássicas instituições universitárias e para os mais recentes colleges e institutos de formação técnico-profissional vocacionalmente orientados ${ }^{4}$. Embora essa diversificação do sistema "clássico" do Ensino Superior tenha se intensificado na segunda metade do século passado, tanto na Europa quanto nos EUA, de fato, ele vem ocorrendo desde meados do século XIX, em países como Alemanha, Inglaterra, Rússia e Estados Unidos, como bem demonstra K. H. Jaraush (1983), em seu estudo comparativo de sistemas de Ensino Superior entre esses quatro países no período de 1860-1930. De acordo com o estudo, no final do século XIX e no início do século XX ocorreu um enorme crescimento relativo dos sistemas de Ensino Superior através de um processo de diversificação institucional. $\mathrm{Na}$ Alemanha, as antigas politécnicas de nível secundário (as Technishe Hochschulen) foram elevadas ao nível terciário em 1875; na Inglaterra, instituições como os British Redbricks deixaram de ser centros de treinamento técnico avançados para se transformarem em instituições universitárias tradicionais. Nos EUA, os colleges vocacionais de 2 anos já dominavam quantitativamente o cenário do Ensino Terciário; na Rússia, os institutos tecnológicos substituíam as universidades tradicionais. De acordo com K. H. Jaraush,

(...) os mecanismos fundamentais em todos os quatro países parecem ser a adição de novos tipos, o upgrading das instituições secundárias existentes e a transformação de sua função na direção do ideal universitário tradicional. (1983, op. cit., p. 19)

Contudo, foi a partir dos anos sessenta, do século passado, que o processo de diferenciação funcional adquiriu "universalidade" como resposta a, pelo menos, três tipos distintos de estímulos que emergiam no contexto das sociedades contemporâneas, quais sejam: a) a demanda por inclusão social; b) a resistência à "abertura" das universidades do tipo "clássico e c) a demanda de formação mais rápida e mais sensível às necessidades da "nova economia" de mão-de-obra qualificada ${ }^{5}$. Ainda que, como veremos mais adiante, esse processo de diferenciação redundou em um sistema de estratificação de instituições de terceiro grau, marcadamente, entre universidades de ensino e pesquisa, universidades de ensino e, na base da pirâmide, instituições de ensino técnico-profissional, sem dúvida foi esse processo que possibilitou o crescimento vertiginoso do acesso à Educação Superior em todo o planeta. Como afirmou Paul Ryan (2003, p. 147), "expansão e vocacionalização têm andado de mãos dadas" ${ }^{\prime \prime}$. De fato, é esse tipo de mudança nos sistemas de Ensino Superior que tem
4. Esse sistema de diversificação, quando polarizado entre o modelo universitário clássico e as instituições de formação técnicoprofissional, como ocorreu na Inglaterra, com a criação dos institutos Tecnológicos no início dos anos 1960, ficou conhecido na literatura como "sistema binário". Nos anos 1980, esses institutos na Inglaterra foram transformados em universidades.

5. Ver Osborne, M. "Increasing or Widening Participation in Higher Education? - a European view", in European Journal of Education, vol 38, n. 1, 2003; Ryan, P. “ Evaluating Vocationalism", in European Journal of Education, vol. 38, n. 2, 2003.

6. "(...) expansion and vocationalisation have gone hand in hand." 
7. "(1) Problematic goals. It is difficult to impute a set of goals to the organization that satisfies the standard consistency requirement of theories of choice. The organization appears to operate on a variety of inconsistent and illdefined preferences. It can be described better as a loose collection of changing ideas than as a coherent structure.

(2) Unclear technology. Although the organization manages to survive and (where relevant) produce, it does not understand its own processes. Instead it operates on the basis of a simple set of trial-and-error procedures, the residue of lerning from the accidents of past experiences, imitation, and inventions born of necessity;

(3) Fluid participation. The participants in the organization vary among themselves in the amount of time and effort they devote to the organization; individuals participants vary from one time to another. As a result, standard theories of power and choice seem to be inadequate; and the boundaries of the organization appear to be uncertain and changing. These properties are not limited to educational institutions; but they are particularly conspicuous there." produzido impactos relevantes, em termos de crescimento e flexibilização, independentemente das várias nuances e conjunturas regionais, nacionais que, obviamente, mediam a maneira de crescimento, adaptando-o às suas peculiaridades.

\section{A questão da gestão organizacional}

De acordo com Michel D.Cohen e James March (1974, p. 3), as universidades de pesquisa constituem uma classe de organizações que podem ser chamadas "anarquias organizadas". As características básicas dessas organizações são:

1 - Objetivos problemáticos. É difícil imputar um conjunto de objetivos a organizações que satisfaçam aos padrões de consistência requeridos pelas 'theories of choice`. A organização parece operar numa variedade de preferências mal definidas e insconsistentes. Ela pode ser melhor descrita como uma coleção frouxa de ideias em mutação do que como uma estrutura coerente;

2 - Tecnologia não clara. Embora a organização consiga sobreviver e (se relevante) produzir, ela não compreende seus próprios processos. Ao contrário, ela opera na base de simples procedimentos de tentativa-e-erro, de resíduos da aprendizagem dos acidentes da experiência passada, da imitação, e de invenções nascidas da necessidade;

3 - Participação fluida. Os participantes da organização variam entre si na soma de tempo e esforço que eles devotam à organização; participantes individuais variam entre os períodos de tempo. Como resultante, as teorias convencionais de poder e escolha parecem ser inadequadas; e os limites da organização são incertos e mutantes.

Essas propriedades não se limitam às instituições educacionais, mas elas são, particularmente, conspícuas nelas. [tradução nossa] ${ }^{7}$

Ainda que, de uma maneira geral, as organizações de Ensino Superior tentem, no sistema formal, combinar uma estrutura decisória burocrática com uma "colegiada", a vida "cotidiana" dessas organizações aproximar-se-á mais à imagem acima descrita do que da de estruturas "racionais", no formato burocrático ou colegiado, buscando implementar objetivos frouxamente definidos. As 
organizações universitárias são altamente complexas em termos de diversificação de área de atuação, dos públicos atendidos e da natureza das atividades desenvolvidas ${ }^{8}$. A estrutura decisória dessas organizações assemelha-se mais àquela de uma polity do que à de uma organização produtiva, ainda que muito complexa. Em cenários organizacionais do tipo acima descrito, predomina a ambiguidade, a incerteza e a disjunção de subsistemas de interesses, de ação e de envolvimento normativo.

\section{Os estudos de caso}

A hipótese básica que guia nossa investigação é que o sistema de gestão característico do tipo de instituição vocacional ou profissionalizante inibe a formação de capital cultural para os estudantes que não tiveram oportunidade de trazer da família esse recurso; ou seja, aqueles estudantes, típicos dessas instituições, de baixo status socioeconômico. Ao falhar em criar capital cultural no ambiente escolar, a formação desses estudantes impõe a eles um teto intransponível na escala de mobilidade ocupacional ${ }^{9}$. No caso brasileiro, as instituições de formação vocacional concentram-se na categoria de entidades de natureza privada. Dentre estas, há uma importante distinção a ser feita: há as instituições tipicamente orientadas para o lucro (for-profit institutions) e aquelas de natureza comunitária ou filantrópica, que vivem a ambivalência de dois tipos de lógica: a da eficiência empresarial e a da "missão institucional". Esse tipo de organização tem sido denominada, na literatura recente, de "organizações híbridas" (KOPPELL, 2003), porque sua estrutura de funcionamento representa um processo de negociação entre as suas duas faces: a privada e a institucional. No outro extremo do contínuo, temos as organizações públicas federais e estaduais de ensino e pesquisa, cuja característica principal é dada pela ambivalência entre as lógicas burocrática e a institucional (PRATES, 2001). Mas esse tipo de instituição está fora do escopo empírico do nosso projeto, pelo fato de que elas, ao contrário dos outros dois tipos organizacionais, não são instituições tipicamente voltadas para a formação profissional-vocacional. Há, contudo, como exceção no contexto do sistema de Ensino Superior brasileiro, uma instituição típica de universidade de pesquisa que, pela definição de sua missão, busca recrutar alunos dos grupos mais baixos de renda familiar, sem assumir, entretanto, o perfil das instituições vocacionais referidas acima. Trata-se da EACH (Escola de Artes e Ciências Humanas), conhecida popularmente como USP-Leste. $O$ que há de peculiar nessa instituição é o seu caráter híbrido, dado, não pela ambivalência entre a lógica empresarial e a institucional, e sim pela sua forte identidade como universidade típica de pesquisa e missão voltada para a formação profissionalizante. Foi essa peculiaridade organizacional que nos levou a incluí-la entre os nossos estudos de caso. Apresentamos, a seguir, nossas hipóteses específicas:
8. Um ótimo trabaIho utilizando esta teoria é apresenta do por R. Whitley (1984), no seu estudo sobre a trajetória da organização dos "campos" científicos no mundo moderno

9. As entrevistas com ex-alunos das instituições privadas, especialmente aquelas for-profit, seria essencial para a comprovação da nossa hipótese. Infelizmente, não conseguimos acesso a essa população por razões práticas: as instituições não tinham cadastro de ex-alunos e não conseguimos, de forma razoável, implementar o método "bola-deneve" para acessála. Nossa hipótese, então, foi discutida apenas com base nas referências empíricas das entrevistas abertas com professores das instituições. 
10. O termo "vocacional" que estamos utilizando aqui refere-se, especificamente, às instituições privadas. Nosso argumento é que esse tipo de instituição no Brasil, com raras exceções, é tipicamente profissionalizante, no sentido vocacional, voltada para a formação de mercado. Nesse sentido, elas são equivalentes àquelas instituições que oferecem cursos técnico-vocacionais de nível pós-secundário nos países europeus. a) Nas instituições mais próximas ao modelo vocacional ${ }^{10}$, não haverá distinção entre estratégias de gestão para o controle acadêmico e o controle administrativo;

b) O tipo de conhecimento enfatizado nas instituições vocacionais de Ensino Superior não contempla as dimensões cognitivas voltadas para a "descoberta", a crítica ou solução de problemas novos. Ao contrário, o conhecimento que professam enfatiza a capacidade cognitiva voltada para a especialização técnica e solução convencional de problemas;

c) O clima acadêmico das instituições vocacionais praticamente inexiste;

d) O perfil dos estudantes das instituições vocacionais é polarizado entre aqueles, em maioria, de origem socioeconômica baixa e aqueles de origem socioeconômica muito alta, havendo muito poucos de origem socioeconômica média.

e) As quatro dimensões acima têm efeitos acumulativos, no sentido de obstruir a criação de capital cultural para os estudantes de baixo nível socioeconômico.

\section{Análise de dados}

Os estudos de caso buscaram identificar, via percepção dos membros do corpo docente, a estratégia geral de gestão acadêmica e administrativa das instituições. A hipótese inicial e a mais geral da pesquisa relaciona duas dimensões básicas:

a) Tipo de instituição: se universitária de pesquisa ou profissional/vocacional;

b) Tipo de natureza administrativa: se mais próxima ao modelo "público" ou ao modelo for-profit.

O cruzamento dessas duas dimensões produz quatro quadrantes: " $a$ " e " $d$ " respresentam tipos consistentes; " $b$ " e " $c$ " representam tipos institucionais pouco prováveis ou inconsistentes. A Figura 1 abaixo ilustra essa proposição. 
Figura 1: Dimensões de tipo de instituição e natureza administrativa

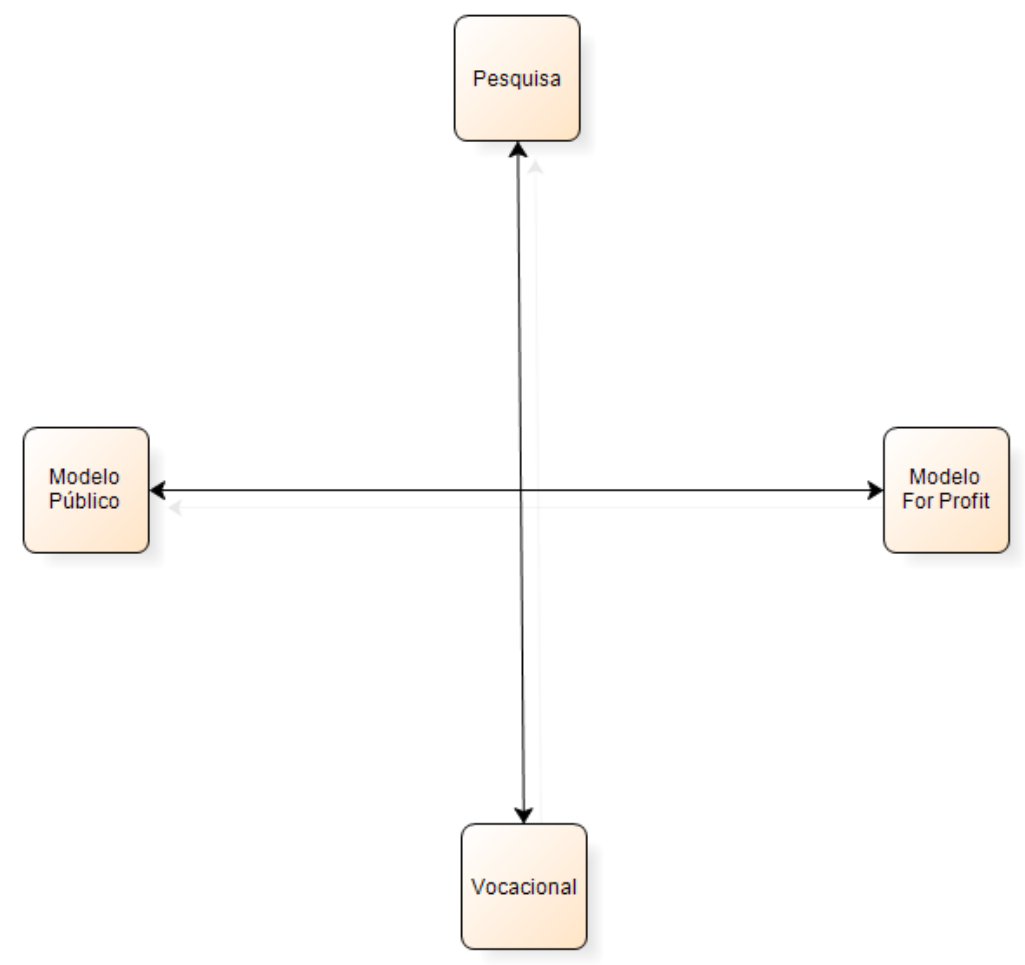

1. As instituições empresariais.

De uma maneira geral, o que encontramos em nossos estudos de caso é que as IES for-profit apresentam um modelo de gestão tipicamente mercantilista ${ }^{11}$ e empresarial. A lógica da eficiência constitui o parâmetro fundamental de avaliação das atividade do corpo acadêmcio na instituição. Qualquer elemento no ambiente institucional que cause tensões com esse parâmetro deverá ser eliminado, incluindo os próprios professores, quando seu comportamento ameaça a eficiência empresarial. Abaixo, apresentamos uma ilustração da percepção generalizada entre os professores dessas instutições ${ }^{12}$.

11. Para uma discussão sobre o conceito desse tipo de gestão, ver Prates (2010).

12. Embora tenhamos uma rica base de entrevistas qualitativas, é impossível, no corpo deste artigo, trazê-las para o texto.

[referindo-se a uma instituição onde é professor] (...) Eles montaram o seguinte, agora lá tem todo um sistema de orçamento, controladoria, eles fizeram uma separação como numa empresa. Hoje a [instituição] funciona como uma empresa. Então, ela tem a parte contábil, a controladoria, compras e o que nós temos que fazer? Nós montamos nossa proposta de orçamento. Cada setor da [instituição] virou uma unidade de negócio. Eu sou da faculdade, a 
Faculdade de Ciências Sociais Aplicadas que é uma unidade de negócio. Eu faço orçamento, eu faço compras, eu faço tudo. Eu tenho um background, eu tenho os prestadores de serviço por trás, então tenho o marketing (...).

A lógica empresarial da eficiência financeira preside claramente a orientação da gestão acadêmica das IES for-profit. O objetivo da administração dessas instituições é eliminar as tensões "naturalmente" geradas pelos dois tipos distintos de objetivos: o acadêmico e o empresarial. Mas, como constatamos pelas falas dos nossos entrevistados, essa tensão é inevitável e o pessoal docente tende a internalizá-la como "algo dado", "externo" ao seu próprio controle. A insegurança do emprego, a instabilidade de suas atividades (cada semestre pode estar com diferentes cursos, com disciplinas, ou sem elas) faz com que os professores se sintam num mercado altamente competitivo e "selvagem", a qualquer momento um "colega" pode "abocanhar" seu espaço, ou sua disciplina pode ser extinta por razões de mercado ou mesmo por medidas de contenção financeira. Essa característica contamina outras dimensões estratégicas para o nível da qualidade acadêmica da formação dos alunos, tais como, ambiente intelectualmente estimulante e do tempo para atividades extraclasse. Nesse contexto, qualquer referência à criação de capital cultural é fora de propósito.

13. Refiro-me, aqui, à ideia de "mimetismo institucional" sugerida por Meyer e Rowan (1991), em que instituições, vistas como exemplares, no ambiente institucional, de um tipo de organização, no caso universidade, tendem a ser copiadas em sua formas estruturais, ainda que de forma ritual. Esse é, tipicamente, o caso, no Brasil, de instituições híbridas buscando referência nas universidades públicas de pesquisa.
2. As instituições híbridas com modelos "quase público" e particular de gestão: o caso das instituições comunitárias/confessionais/filantrópicas.

Essas instituições vivem dramaticamente as tensões da convivência entre os dois modelos opostos de gestão organizacional: o modelo frouxo, anárquico das universidades de pesquisa, e o empresarial, gerencialista, das instituições forprofit de Ensino Superior. Essas são as instituições híbridas obrigadas a conviver com duas lógicas mutuamente inconsistentes: a lógica institucional e a lógica empresarial. Enquanto as instituições empresariais funcionam com objetivos claros e unívocos, as híbridas vivem a ambiguidade e as incertezas relacionadas à definição de "missões" institucionais e objetivos organizacionais desacoplados e inconsistentes entre si. Essa situação é frequentemente expressa pelos nossos entrevistados.

Contudo, é importante salientar que o potencial de conflito, a busca pela identidade de uma instituição acadêmica de pesquisa e, principalmente, o "grupo de referência"13 do corpo docente das instituições híbridas geram incertezas e ambiguidades que funcionam como obstáculos à implementação do modelo administrativo das instituições tipicamente empresariais. Nesse sentido, o hibridismo gera um contexto organizacional mais próximo ao modelo das 
instituições acadêmicas do que as instituições do tipo empresarial.

Mas, por outro lado, os dilemas postos por essa inconsistência de lógicas distintas de ação, produzem situações que limitam o espaço da atividade tipicamente acadêmica como a de orientação de alunos e de desenvolvimentos de projetos de pesquisa. Ao tentarem sustentar essas duas faces, a acadêmica e a empresarial, essas instituições criam verdadeiras parafernálias administrativas para manter o controle estrito sobre as atividades dos docentes, que são obrigados a despender um enorme volume de energia para assegurar um pouco da sua autonomia duramente conseguida. Veja, por exemplo, o texto abaixo, retirado de uma entrevista com uma professora doutora sênior e com uma enorme experiência em pesquisa de prestação de serviços dentro da própria instituição. Perguntada sobre como consegue tempo (horas) para realização de pesquisas dentro da instituição, ela assim expressou:

(...) [um professor] por exemplo, ele é aulista e não é regime (de 40 horas), eu sei que ele tem muitas turmas, eu não sei se são 4 ou 5 turmas e, ao mesmo tempo, ele está lá no Instituto de Pesquisa [Instituto coordenado pela entrevistada]. Lá no Instituto ele tem horas semanais, pra estar lá na equipe do colegiado do Instituto, aí ele tem um contrato aditivo e é a Instituição que paga, porque o Instituto (...) é reconhecido pela Instituição e nós temos um banco de horas, é tem esse negócio de banco de horas também.

Percebe-se, então, que, mesmo nessas instituições híbridas, há uma enorme dificuldade para se criar um ambiente acadêmico estimulante. Os professores/ pesquisadores conseguem realizar projetos extraclasse, apesar, e não pelo estímulo, do sistema de gestão.

3. Instituição Híbrida: face acadêmica e vocacional.

O caso da EACH - Escola de Artes, Ciências e Humanidades (USP-Leste)

O "caso" da USP-Leste, como é popularmente conhecida a EACH, constitui um modelo ímpar, ainda experimental de Instituição ${ }^{14}$ no ambiente institucional de modelos organizacionais de instituições de Ensino Superior. Distintamente dos institutos de tecnologias de terceiro grau da Alemanha, França, Polônia, GrãBretanha, Países Escandinavos ou dos Community Colleges dos USA, enfim, da grande maioria do que se denomina de sistema terciário de Ensino Superior no mundo atual, o modelo USP-Leste pretende constituir uma instituição híbrida sui generis: ela pretende combinar a lógica de funcionamento das instituições de pesquisa incrustadas nas universidades tradicionais de elite, com a lógica 
15. Para maior detalhes desse tópico, ver Faleiros (2011), no qual foi baseado.

16. Ainda foram cortados do banco vários casos de alunos de Ensino Superior que não apresentavam informações se sua formação foi obtida em sistema público ou privado. Após esse procedimento, foi utilizado o peso da PNAD, para inferência sobre os dados populacionais, no ano de 2007. Portanto, neste trabalho, só foram incluídos aqueles indivíduos que já tinham concluído Ensino Superior e estavam no mercado de trabalho, no ano de referência, 2007. de funcionamento das instituições voltadas para a profissionalização centrada no mercado de trabalho. A grande inovação institucional é a criação de um ciclo básico propedêutico centrado na metodologia de Resolução de Problemas.

Como foi mostrado nas seções anteriores deste artigo, a expansão do sistema de Ensino Superior, no último quartel do século passado, deu-se por dois mecanismos: expansão de vagas nos institutos de tecnologia, estes muitas vezes recém atualizados do nível pós-secundário para o terciário, ou pela diversificação institucional de grandes universidades que criavam campi especializados, para absorver a maioria dos estudantes voltados para profissionalização do mercado de trabalho.

Aparentemente, o modelo USP-Leste sugere inserir-se nesse último modelo, entretanto, como trataremos de mostrar, a orientação do seu corpo docente difere bastante. Há uma orientação explícita para criação de capital cultural, no estilo mais convencional das universidades de elite, a partir de um novo modelo pedagógico voltado para a melhoria da capacidade cognitiva dos alunos. Vejamos uma expressão dessa "missão" institucional nas falas dos nossos entrevistados: "A gente quer diferenciar da seguinte forma, podemos pegar pessoas que não têm certa condição social ou privilegiada e transformá-las também em cientistas."

De outra parte, seus cursos, bacharelado e licenciatura, são todos de longa duração (4 anos). Situada na região leste de São Paulo (Guarulhos), a mais densa e pobre da região metropolitana de São Paulo, a USP-Leste seleciona seus alunos pelo vestibular único da USP e oferece curso profissionalizantes não convencionais, porém, com maior atratividade de mercado. A instituição vive, hoje, um claro dilema resultante do hibridismo entre uma missão voltada para a inclusão social e, portanto, orientada mais para um modelo vocacional, ou uma missão voltada mais para a tentativa de combinar o modelo de universidade-pesquisa, mantendo a "linhagem materna", com a de inclusão social, criando capital cultural entre os estudantes vindos dos setores de classe mais baixa.

\section{O estudo quantitativo ${ }^{15}$}

Com base em dados da PNAD, tentamos testar algumas hipóteses sobre o efeito do modelo institucional da organização de Ensino Superior sobre o desempenho dos seus formandos no sistema de mobilidade ocupacional. Nesse trabalho, fizemos um recorte apenas com alunos que já tinham Ensino Superior completo e que estavam no mercado de trabalho ou que dispunham dessas informações no banco original ${ }^{16}$. 
A pesquisa procurou comparar os efeitos dos formatos institucionais ${ }^{17}$ diferenciados em tradicional/tecnológico ${ }^{18}$ e público/privado segundo a posição de prestígio ocupacional do indivíduo. Sob a ótica da inserção e prestígio ocupacional no mercado de trabalho dos egressos, há uma forte diferenciação entre as instituições públicas e privadas, no Brasil, mesmo quando se observam instituições tecnológicas (PRATES, 2005; SCHWATZMAN, 2005). A nossa variável independente se divide em quatro categorias: Ensino Tradicional Público, Ensino Tradicional Privado, Ensino Tecnológico Público e Ensino Tecnológico Privado. O objetivo principal é analisar o prestígio diferenciado da credencial educacional segundo o tipo de instituição e/ ou curso na estrutura ocupacional ${ }^{19}$.

Nesse estudo, propusemos 4 modelos de regressão para a discussão do retorno da credencial por modelo de Ensino Superior em relação ao seu prestígio ocupacional no mercado de trabalho. Utilizamos as mesmas variáveis de controle e a mesma variável dependente para todos os modelos. A variável independente foi recodificada de um modelo para o outro, de acordo com o nosso objetivo analítico.

\section{Variável dependente}

A variável dependente para os 4 modelos de regressão que foram selecionados para a análise de dados é o prestígio ocupacional. Aplicamos o Índice Internacional de Prestígio de Ocupacões de Treiman ${ }^{20}$ ao código brasileiro de ocupações (CBO) presente na PNAD. O Índice varia de 6 a 78, mas no caso dos nossos dados, o índice variou de 18 a 78. Ele estabelece uma hierarquia de ocupações em que quanto menor o valor, mais baixo o prestígio associado à profissão, e quanto maior o valor, maior o prestígio do cargo.

\section{Variável independente}

A variável independente é "Tipos de Ensino Superior". Essa variável foi desdobrada como estratégia para o teste diferenciado de categorias em: Ensino Tradicional Público, Ensino Tradicional Privado, Ensino Tecnológico Público, Ensino Tecnológico Privado. Para cada modelo, criou-se uma variável dicotômica. Nos modelos, foram usadas como referência as variáveis relativas aos modelos públicos: tradicional, para os 3 primeiros modelos de regressão, e tecnológico, para o último. Para cada modelo de regressão, foram retirados da amostra os casos pertencentes às outras categorias da variável independente.
17. Embora na seção I (estudo qualitativo) deste artigo tenhamos utilizado um modelo de diferenciação institucional que incluiu as nuances de natureza administrativa - pública, confessional/comunitária e empresarial -, no caso do estudo quantitativo os dados disponíveis não permitiram o mesmo critério de diferenciação. Fomos, então, obrigados, por essa limitação, a diferenciar as instituições na forma acima proposta, lembrando que a distinçào privada/ pública certamente contamina a outra dimensão bachaelado/tecnológico. Enquanto na seção I foi possivel, pela nautreza qualitativa do estudo, tratar como "modelo vocacional" inclusive os cursos de bacharelado do setor privado, no estudo quantitativo mantivemos a distinção entre a natureza administrativa do curso e o seu formato institucional - bacharelado/tecnológico.

18. Chamamos de "Ensino Tradicional" os cursos de bacharelado e licenciatura, que têm um formato mais próximo do modelo clássico de liberal arts, enquanto o "Ensino Tecnológico" é aquele típico do modelo "vocacional" apresentado na seção I. 
19. É uma pena que o suplemento sobre educação profissional só tenha ocorrido uma única vez, no ano de 2007, fato que impossibilitou uma comparação de séries históricas, temporais da PNAD.

20. Em relação aos variados tipos de índices socioeconômicos, ocupacionais, o presente trabalho utilizou as sintaxes preparadas por Flávio Carvalhaes, apresentadas e disponibilizadas num workshop sobre o tema, no grupo de pesquisa sobre estratificação, vinculado ao Núcleo de Avaliação de Políticas Sociais (Naps). Nossos agradecimentos ao Flávio Carvalhaes pela disponibilidade para o uso de seu trabalho com as recodificações dos códigos.

21. Destaca-se que apenas " $X_{1}$ " variou de um modelo para o outro, que se refere às variáveis independentes para cada proposição empírica.

22. Utilizaremos tradicional para se referir aos cursos de bacharelado e licenciatura em contraposição ao curso tecnológico, que fornece a habilitação de tecnólogo.

\section{Modelos de regressão}

Foram elaborados 4 modelos para testar a relação entre tipos de sistemas de Ensino Superior e o prestígio ocupacional dos egressos desses sistemas. Abaixo, apresentamos as hipóteses e os resultados e análise de cada modelo. A seguinte formula resume os quatro modelos ${ }^{21}$ :

$$
Y=\alpha+\beta_{1} X_{1}+\beta_{2} X_{2}+\beta_{3} X_{3}+\beta_{4} X_{4}+\beta_{5} X_{5}+\varepsilon
$$

Onde,

$$
\begin{aligned}
& Y=\text { Índice de Prestígio de Treiman } \\
& \alpha=\text { Constante } \\
& X_{1}=\text { Variável Independente }- \text { Tipos de Ensino Superior (dummy) } \\
& \text { Variáveis de controle: } \\
& X_{2}=\text { Sexo (dummy) } \\
& X_{3}=\text { Cor ou raça (dummy) } \\
& X_{4}=\text { Idade } \\
& X_{5}=\text { Idade Quadrática } \\
& \varepsilon=\text { Erro Estocástico }
\end{aligned}
$$

3.1. Modelo mais geral tomando o Ensino Público como referência em relação a todos os outros.

Hipótese: No Brasil, o Ensino Público nos cursos tradicionais sempre foi de excelência e de elite, garantindo sempre os melhores postos no mercado de trabalho, com maior prestígio em relação aos demais (PRATES, 2005; SCHWARTZMAN, 2001).

Esse modelo contou com todos os indivíduos formados no Ensino Superior (419.746); seja bacharelado, licenciatura, tecnológico, público ou privado. Tomou-se aqueles formados no Ensino Superior "tradicional"22 público como referência por representar justamente o modelo de elite no Brasil em contraposição aos demais. O primeiro modelo utilizou todos os outros modelos numa mesma categoria. O objetivo era justamente testar a hipótese de preponderância do modelo de elite em relação aos demais, qual o retorno de status diferenciado no mercado de trabalho, segundo modelo de instituição universitária.

Os resultados indicam que todas as variáveis do modelo apresentaram significância estatística. O $R^{2}$ foi de 0,147 , isto é, $14,7 \%$ da variação do Índice de Prestígio Ocupacional de Treiman pode ser explicada pelos efeitos do ensino tradicional público e das variáveis de controle explicitadas no modelo. A variável independente, de teste propriamente, confirma a hipótese de que os 
indivíduos formados no bacharelado ou licenciatura do Ensino Público ocupam cargos de maior prestígio no mercado de trabalho em relação a todos os outros indivíduos: sejam eles formados em bacharelado e licenciatura do Ensino Privado ou nos cursos de tecnólogos. O resultado aponta que ser formado no ensino tradicional público confere 9 pontos no Índice de Prestígio Ocupacional de Treiman a mais do que ser formado nos outros sistemas de ensino.

3.2. Modelo 2: Somente casos de ensino tradicional para a ver as diferenças de status entre público e privado

Hipótese: No Brasil, o Ensino Privado cumpriu o papel do sistema vocacional, quase inexistente no país, de absorver as classes menos favorecidas e foi o grande propulsor da expansão do Ensino Superior, porém seus egressos não conseguiram o mesmo prestígio daqueles formados no Ensino Tradicional Público, de elite (PRATES, 2005; SCHWARTZMAN, 2001)

O Modelo II utilizou as mesmas variáveis do primeiro modelo, porém houve um filtro no número de casos. A amostra ficou restrita aos casos de indivíduos no mercado de trabalho com formação de bacharel ou licenciado (269.678). O principal intuito é analisar a diferença de status ocupacional entre o modelo público, historicamente de elite, e o privado que desempenha o papel do Ensino Vocacional Profissionalizante no país, visto que esse sistema de ensino, como o tecnológico, é ainda muito recente no Brasil.

Todas as variáveis do modelo apresentaram significância estatística. O $\mathrm{R}^{2}$ foi de 0,122, sendo $12,2 \%$ da variação do Índice de Status Ocupacional explicada pelos efeitos do sistema público tradicional e das variáveis de controle. A hipótese de que o modelo de Ensino Superior público aufere um prestígio maior no mercado de trabalho em relação ao privado foi confirmada. O fato de ser formado no Ensino Superior público aumenta em quase 6 pontos no índice de prestígio de Treiman em relação a ser formado no Ensino Superior privado.

Nota-se, em relação ao modelo anterior, tendo também o modelo tradicional público como referência, mas contando com menos casos, que o Modelo II explica menos a variação do Índice de Prestígio Ocupacional de Treiman pelas mesmas variáveis. Isso pode ser comparado através da diferença entre $R^{2}$ dos dois modelos, que ainda é muito sutil, mas que revela que o primeiro modelo tem um melhor ajuste. 
3.3. Modelo 3: Somente casos de Ensino Público tradicional e tecnológico para a ver as diferenças de status entre o perfil mais acadêmico e o mais vocacional.

Hipótese: No Brasil o Ensino Tecnológico orienta-se para suprir demandas de qualificação profissional mais rápida, refletindo o processo de diferenciação institucional do sistema brasileiro de Ensino Superior, constituindo, assim, um meio de expansão do sistema de Ensino Superior e de oportunidade de acesso a esse nível para as pessoas vindas dos setores de baixa renda, mas, ao mesmo tempo, condenando-os à ocupações com menor status ocupacional no mercado de trabalho (PRATES, 2005; SCHWARTZMAN, 2001; NEAVE, 2000; ROKSA, 2008).

O Modelo III se diferencia do Modelo II ao serem retirados os casos de indivíduos com Ensino Tradicional Privado e , em seu lugar, colocados os indivíduos com Ensino Tecnológico. Portanto, a amostra (263.634) buscou comparar o sistema público de elite com o modelo tipicamente vocacional. Em todo o mundo, o fenômeno da diferenciação institucional está ligado estreitamente à expansão do acesso ao Ensino Superior. No Brasil, embora o Ensino Tecnológico seja recente, optamos por esse modelo para dar um panorama de como se dá a diferença de prestígio dos cargos ocupados por aqueles provenientes de elite versus aqueles do modelo vocacional puro. O Ensino Tradicional Privado foi excluído da amostra por estar, no caso brasileiro, mais próximo ao modelo vocacional do que ao modelo clássico.

O Modelo III também apresenta significância estatística para todas variáveis. 0 $\mathrm{R}^{2}$ foi de 0,257 ; explicando $25,7 \%$ da variação no Índice de Status Ocupacional de Treiman pelos efeitos da variável independente, o sistema público de elite, e as variáveis de controle. A hipótese de diferenciação de status ocupacional produzido pelo modelo público tradicional e o vocacional foi confirmada. O fato de ter se formado no ensino tradicional público confere 12,7 pontos a mais na escala do Índice de Prestígio de Treiman em relação àqueles vindos do Ensino Tecnológico.

Nota-se uma melhora considerável do modelo III em relação aos demais. O $\mathrm{R}^{2}$ praticamente dobrou, o que expressa que as variáveis do modelo III explicam melhor a variação no Índice de Status Ocupacional de Treiman. Outro ponto a ser ressaltado é o alto valor de status diferenciado (12,7 pontos) entre aqueles do sistema de elite tradicional e aqueles do sistema tecnológico. 
3.4. Modelo 4: Somente casos de Ensino Tecnológico para a ver as diferenças de status entre público e privado.

Hipótese: No Brasil, já se observa uma diferença de status entre aqueles indivíduos provenientes do Ensino Tecnológico Público em relação àqueles do Ensino Tecnológico Privado. Os indivíduos formados no Ensino Tecnológico Público (Sistema S, e Fatecs) têm melhor desempenho no mercado de trabalho do que aqueles formados nos cursos tecnológicos do sistema privado (SCHWARTZMAN, 2005).

O Modelo IV buscou diferenciar os indivíduos do Ensino Tecnológico por situação administrativa: se foram formados no sistema público ou privado. Nesse caso, a amostra foi composta somente por indivíduos do sistema tecnológico (150.068). O Modelo IV apresentou significância estatística para todas as variáveis. O $R^{2}$ foi de 0,068 . Portanto, 6,8 \% da variação no Índice de Status Ocupacional está sendo explicada pelas variáveis do modelo. Houve uma diferenciação entre o sistema tecnológico público e o sistema tecnológico privado. Porém se observa uma diferenciação bem menor, se compararmos com os modelos anteriores. $\mathrm{O}$ fato do indivíduo ter se graduado no Ensino Tecnológico Público aumenta em 2,8 pontos no Índice de Status Ocupacional de Treiman, em relação àqueles provenientes do Ensino Tecnológico Privado.

O quarto modelo se mostrou mais frágil que os demais para explicar as diferenças de status. A capacidade explicativa do modelo foi bem menor que a observada nos outros modelos, explicando somente $6,8 \%$ da variação do Índice de Pretígio de Treiman. Ainda assim, pode-se dizer que há indícios de uma diferenciação de prestígio ocupacional por aqueles com diploma do Ensino Tecnológico Público em relação aqueles do Ensino Tecnológico Privado, ainda que pequeno.

Os modelos propostos foram amparados na discussão da literatura sobre a expansão e massificação do Ensino Superior, a diferenciação institucional e a estratificação das instituições de Ensino Superior, segundo modelo.

\section{Conclusão}

Este estudo discutiu o dilema da expansão do sistema de Ensino Superior vs. a sua democratização, vista à luz da tendência histórica de diferenciação institucional que redundou em estratificação institucional.

Nossos estudos de caso chamaram a atenção para o fato de que um dos fatores importantes, que indicam a estratificação das instituições de Ensino Superior, é o tipo de gestão a que estão submetidos os diferentes tipos de instituições, as de elite (acadêmicas de pesquisa), e aquelas "vocacionais" ou 
profissionalizantes. No caso das primeiras, o ambiente ou clima acadêmico, alimentado por valores que enfatizam criatividade, ousadia intelectual e descoberta científica, estimula a criação de capital cultural necessário àquelas ocupações, que gozam de certa autonomia e possuem influência social e política no sistema social maior da sociedade. Já as segundas são geridas por sistemas gerenciais que enfatizam eficiência e resultados de curto prazo, aprendizagem disciplinada e ênfase na especialização técnica. Obviamente, esse modelo de gestão acadêmica é incapaz de gerar capital cultural necessário para determinação de chances de mobilidade ocupacional para atingir ocupações de alto nível no mercado de trabalho. Essas conclusões podem ser sintetizadas pelo seguinte diagrama:

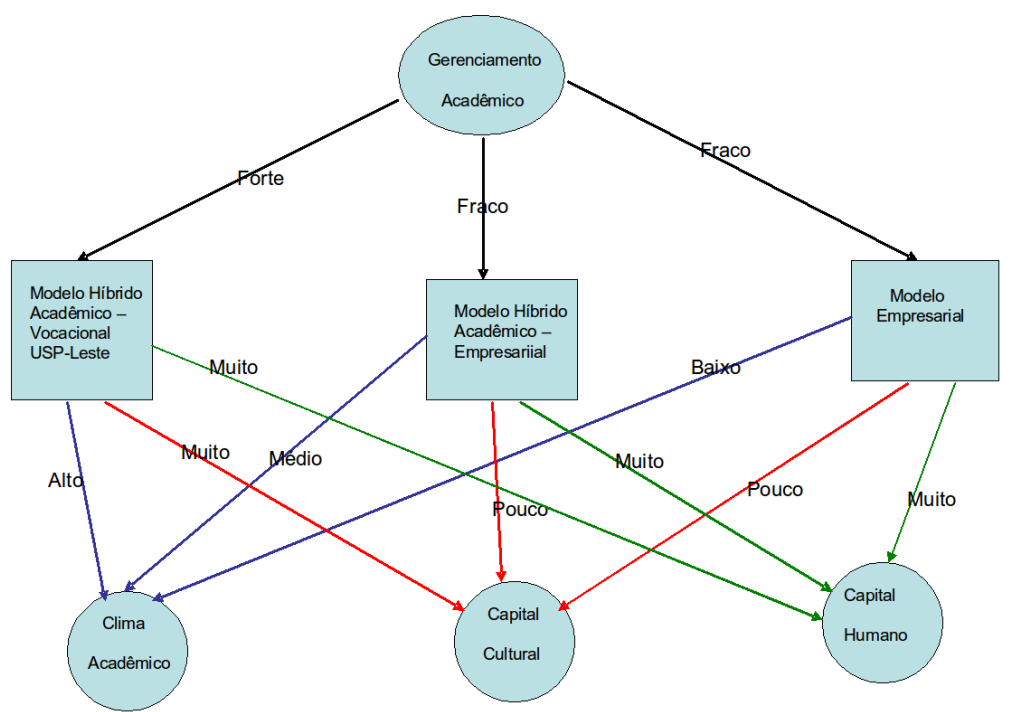

Já o estudo quantitativo mostra que as hipóteses e evidências qualitativas dos estudos de caso sustentam-se quando analisamos os modelos de regressão, construídos para testar as hipóteses relacionadas ao efeitos da variável independente "natureza administrativa das instituições de Ensino Superior" e a posição relativa dos seus egressos na escala de prestígio ocupacional de Treiman. Os resultados mostram que, para os quatro modelos, encontramos diferenças relevantes no sentido de nossas hipóteses: o sistema público de elite propicia cargos de maior prestígio do que os outros, como reforçam os 3 primeiros modelos analisados, destacando-se a maior diferença, entre os modelos analisados, no modelo 3, com grande diferenciação entre o modelo de elite e o modelo tecnológico, mais vocacional. Observamos, também, que o modelo IV aponta diferenças de prestígio ocupacional entre o setor público e privado do 
sistema tecnológico, embora este tenha apresentado menor consistência quando comparado aos outros.

Concluindo, podemos afirmar que há uma estratificação de modelos do Ensino Superior evidente no Brasil, que se reflete posteriormente no prestígio dos cargos que os indivíduos ocuparão no mercado de trabalho. Contudo, é importante a ressalva de que os dados são insuficientes para que se queira comprovar algo definitivo em relação ao prestígio ocupacional dado pela formação de origem. Indica-se um bom caminho a ser percorrido em pesquisas posteriores. Os resultados podem ser expressos pela tabela 1 e a figura 3 .

Tabela 1: Comparação de modelos quantitativos

\begin{tabular}{ccc}
\hline MODELOS & VARIÁVEIS TESTE & COEFICIENTES \\
\hline MODELO I & $\begin{array}{c}\text { Ensino Tradicional } \\
\text { Público vs os tipos de } \\
\text { ensino superior juntos }\end{array}$ & 5,744 \\
MODELO II & $\begin{array}{c}\text { Ensino Tradicional } \\
\text { Público vs Ensino } \\
\text { Tradicional Privado }\end{array}$ & $\mathbf{9 , 0 0 3}$ \\
\hline MODELO III & $\begin{array}{c}\text { Ensino Tradicional } \\
\text { Público vs Ensino } \\
\text { Tecnológico }\end{array}$ & 12,697 \\
\hline MODELO IV & $\begin{array}{c}\text { Ensino Tecnológico } \\
\text { Público vs Ensino } \\
\text { Tecnológico Privado }\end{array}$ & 2,804 \\
\hline $\begin{array}{l}\text { Varável dependente: Índice de prestígio de Treiman } \\
\text { Fonte: PNAD 2007. Elaborada pelos autores }\end{array}$
\end{tabular}


Figura 3: Síntese dos resutlados quantitativos

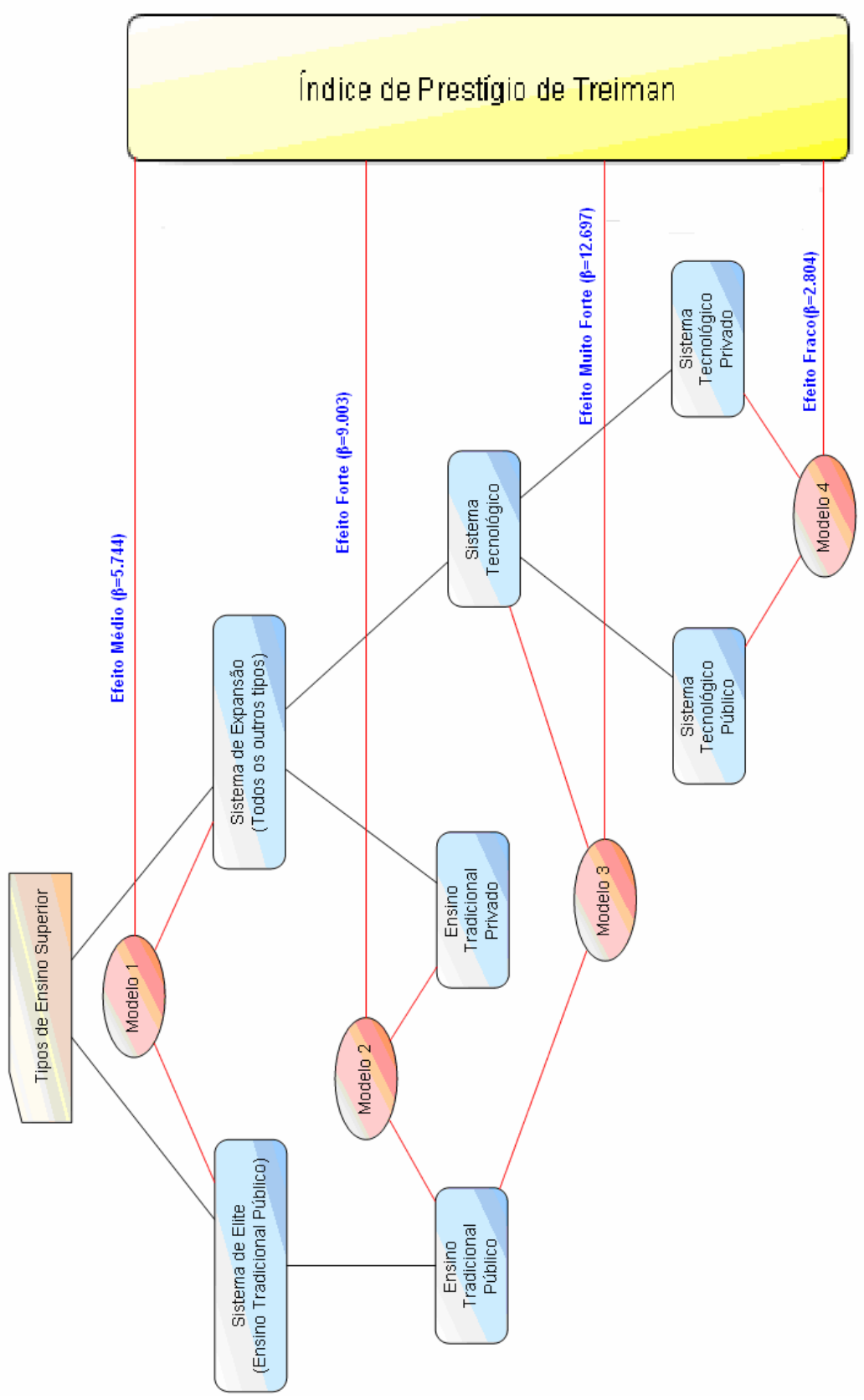

Fonte: PNAD, 2007. Elaborado pelos autores. 
Abstract: This article discusses the effect of the relationship between types of organizational management of institutions of higher education and its effects on the performance of their graduates in the labor market, in terms of access to positions of higher occupational prestige (PRATES, 2007; 2010). The article brings together two independent studies on this issue. The first one is a case study, conducted in 2008, with faculty members of private institutions of higher education and with faculty members of a public university, the EACH (USP-Leste). The second is a quantitative study, conducted in 2011, with data from the PNAD 2007 with the purpose of testing, through linear regression models, whether either the type of institution - public or private, or/and the type of course, baccalaureate or technological - affects student performance in terms of unequal access to jobs with higher prestige in the labor market. The main conclusion, though not a definitive one, is that the Prates' hypothesis (2007; 2010) is a plausible one, namely that the institutional environment generated by the type of internal organizational management of the institution of higher education affects the level of student performance for getting the jobs of higher occupational prestige in the labor market.

Keywords: Academic Climate, Vocational Institutions, Occupational Prestige, Cultural Capital, Labor Market

\section{Referências Bibliográficas}

COHEN, M. D.; MARCH, J. G., OLSEN, J. P G. "Can Model of Organizational Choice". Administrative Science Quartely, 17, n.1, 1972, p. 1-25.

COLLARES, A. C. M. Educational Inequalities and the Expansion of Postsecondary Education in Brazil, from 1982 to 2006. PhD thesis in Sociology Winsconsin University-Madison, 2010.

FALEIROS, M. Expansão do Ensino Superior e Diferenciação Institucional: Uma Análise Comparativa do Efeito dos Modelos Clássicos e Vocacionais sobre o Status Ocupacional de seus Egressos. Dissertação de mestrado em Sociologia, UFMG, 2011.

JARUSCH, H. K. "Higher Education and Social Change: some comparative perspectives", in Konrad, H. J. (org), The Transformation of Higher Education 18601930. Chicago: University of Chicago Press, 1983, p. 9-36.

KOPPELL, J. G. S. The Politics of Quasi-Government: Hybrid Organizations and the Dynamics of Bureaucratic Control. Cambridge: Cambridge University Press, 2003. 
LUCAS, S. R. "Effectively Maintained Inequality: Education Transitions, Track Mobility, and Social Background Effects." The American Journal of Sociology, 106 (6), 2001, p. 1642.

MEYER, W. J.; ROWAN, B "Institutionalized Organizations: formal structure as myth and ceremony", in Walter Powell e Paul J. DiMaggio (eds.), Institutions and Organizations. Chicago: University of Chicago Press, 1991.

NEAVE, G. "Diversity, differentiation and the market: the debate we never had but which we ought to have done". Higher Education Policy, 13, 2000, p. 7-21.

OSBORNE, M. "Increasing or Widening Participation in Higher Education? - a European view". European Journal Of Education, vol. 38, n. 1, 2003.

PRATES, A. A. P. "Universidade-Empresa ou Universidade vs. Empresa?", in Universidade - Indústria. Pespectivas da UFMG. Belo Horizonte: UFMG, 1999.

. "A Questão do gerenciamento das IFES no Cenário de Autonomia", in Durham, R. E. e Sampaio, H. (orgs.) O Ensino Superior em Transformação. São Paulo: NUPES/USP, 2001.

. Os Sistemas de Ensino Superior na Sociedade Contemporânea: Diversificação, Democratização e Gestão organizacional - O caso brasileiro. Tese de doutoramento em Sociologia, Universidade Federal de Minas Gerais, 2005.

. "Universidades vs. Terciarização do ensino superior: a lógica da expansão do acesso com manutenção da desigualdade - caso brasileiro". Sociologias, Porto Alegre, ano 9, n 17, p. 102 -123, 2007.

RAFTERY, A.; HOUT, M. “Maximally Maintained Inequality: Expansion, Reform, and Opportunity in Irish Education, 1921-75". Sociology of Education, 66 (I), 1993, p. 41-62.

ROKSA, J. "Structuring access to higher education: The role off diferentiation and privatization". Research in Social Stratification and Mobility, 26, 2008, p. 57-75.

RYAN, P. "Evaluating Vocationalism". European Journal of Education, 38, n. 2, 2003, p. 147-162.

SCHWARTZMAN, S. A expansão do ensino superior, a sociedade do conhecimento, e a educação tecnológica. SENAI, Departamento Nacional, 2005, 58p.

. "O Viés Acadêmico na Educação brasileira", in Bacha, L. E. e Schwartzman, S. (orgs), Brasil: a nova agenda social, Rio de janeiro: LTC, 2011.

SHAVIT, Y.; ARUM; R; GAMORAN, A.; MENAHEM, G. (eds) Stratification in Higher Education: A Comparative Study. Stanford University Press: Stanford, 2007. 